\title{
Automatisierung auf dem Vormarsch
}

\section{Liebe Leserin, lieber Leser,}

die Formula Student Germany war in diesem Jahr so international wie nie zuvor: Fast 120 Teams aus 25 Ländern gingen am Hockenheimring an den Start, darunter Teilnehmer aus Indien, China, Russland, Lettland und sogar Australien.

Harte Arbeit, technisches Verständnis und Disziplin, aber auch Sponsoren steigern die Chance auf den Sieg. Unabdingbar ist, das im Laufe der Zeit gewonnene Know-how allen Teammitgliedern $\mathrm{zu}$ vermitteln. In jeder Saison formieren sich die Teams neu, weil Mitglieder ihr Studium beenden oder ein Auslandssemester ansteht. Um vorne mitzufahren, ist der Wissenstransfer entscheidend, berichtet Christoph Zinke, ehemaliger FSG-Teilnehmer, im Interview. Prof. Dr. Stefan Gies von Volkswagen bekräftigt im zweiten Interview, dass Erfolg nur durch Teamwork möglich ist.

Wie in einem Getriebe greifen bei der Formula Student viele Zahnräder ineinander, um das Vorwärtskommen zu ermöglichen. Sponsoren aus Industrie und Wirtschaft, freiwillige Helfer, aber auch Universitäten und Hochschulen, die den Studierenden den benötigten Freiraum geben, machen die Formula Student zu einem unvergesslichen Erlebnis.

Die Begeisterung ist überall im Fahrerlager sichtbar, und das spüren auch die OEMs, Zulieferer und Entwicklungsdienstleister, die vor Ort um den Nachwuchs werben. Junge Leute mit frischen Ideen und einer besonderen Herangehensweise, Probleme zu lösen, sind in der Automobilindustrie gefragt die FSG hat sich als Jobbörse etabliert.

Wie in der konventionellen Automobilentwicklung macht sich die zunehmende Automatisierung auch in der Formula Student bemerkbar: Die Organisatoren gaben bekannt, dass im Jahr 2021 nur noch die zwei Klassen Combustion und Electric erlaubt sind, diese aber das Beschleunigungsrennen im Driverless-Modus fahren müssen. Bis dahin empfehlen wir einen Besuch der Formula Student 2019 - diese findet vom 5. bis 11. August am Hockenheimring statt.

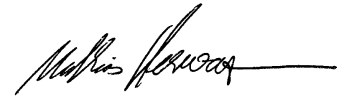

Mathias Heerwagen Redaktion ATZ/MTZ

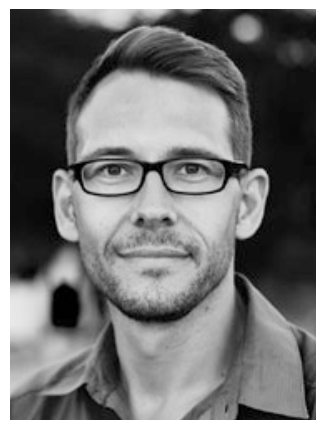

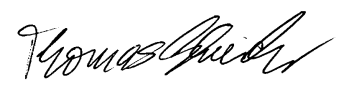

Thomas Schneider Redaktion ATZ/MTZ

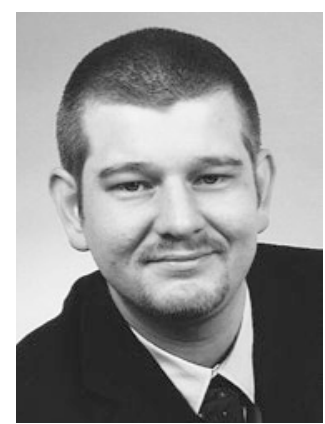

SEIT 1898 DER

ANTRIEB VON

AUTOMOBIL-

UND FAHRZEUG-

TECHNIK

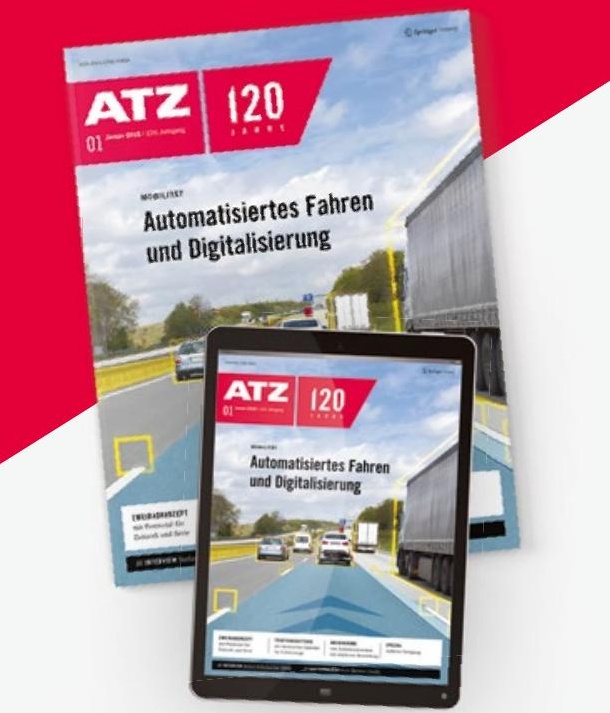

\section{JETZT UNVERBINDLICH TESTEN UND JUBILÄUMS- GESCHENK SICHERN}

www.meinfachwissen.de/atz/probe 